\title{
Semeadura direta de milho com dois tipos de sulcadores de adubo, em nível e no sentido do declive do terreno
}

\author{
No tillage of corn with two types of fertilizer furrow across and towards the slope of land surface
}

\author{
Renato Levien ${ }^{\mathrm{I}}$ Carlos Eduardo Angeli Furlani ${ }^{\mathrm{II}}$ Carlos Antônio Gamero ${ }^{\mathrm{III}}$ Osmar Conte ${ }^{\mathrm{IV}}$ \\ Fábio Alexandre Cavichioliv
}

\section{RESUMO}

O presente estudo teve como objetivo avaliar parâmetros operacionais de um conjunto mecanizado envolvendo trator e semeadora, assim como o rendimento da cultura do milho semeada nas diferentes configurações das máquinas e combinações com o ambiente de produção. Os tratamentos consistiram de tipos de sulcadores (discos duplos $e$ hastes), os quais foram avaliados em experimentos em que a operação de semeadura direta do milho foi efetuada transversalmente ao declive (em nível) e em aclive e declive. A semeadura contra o declive e o uso de haste sulcadora implicaram maior demanda de esforço de tração, patinagem do trator e consumo de combustível por área trabalhada e não influenciaram o volume de solo mobilizado, a população de plantas e a produtividade de grãos do milho, em relação à operação realizada em declive e uso de sulcador de discos duplos, respectivamente. A utilização de sulcador do tipo haste resultou em menor número de plantas acamadas e quebradas, em relação ao uso de discos duplos, independentemente do sentido da operação. A principal diferença entre semear em nível ou em declive é a formação de sulcos orientados no sentido do terreno, pela ação de sulcadores do tipo haste e elevada patinagem dos rodados do trator, já que o consumo de combustível por área trabalhada e capacidade operacional não foram afetados por aquelas variáveis.

Palavras-chave: semeadora-adubadora, força de tração, consumo de combustível, produtividade de milho.

\section{ABSTRACT}

This study aimed to evaluate the operational parameters of a series of mechanized tractor and seed drill, and corn yield planted in different settings and combinations of machines with the production environment. Treatments consisted of types of fertilizer furrow (double discs and shanks), which were tested in experiments in which the operation of corn direct seeding was performed across the slope (in level) and direction of slope (for and against). Sowing against the slope and the use of shank implied a higher demand of traction effort, skating the tractor and fuel consumption per area worked, and didn't affect the volume of soil mobilized, population of plants and grain yield of corn in relation to the operation for the use of slope and furrow discs doubles, respectively. The use of furrow shank type $t$ resulted in fewer plants broken and lodged plants in relation to the use of double discs, regardless of the direction of operation. The main practical difference between level sow or direction of the slope is the formation of grooves oriented in the same direction, by the action of furrow shank and the high shaft of the tractor wheel slip since the fuel consumption per area worked and operation capacity were not affected by those variables.

Key words: seed drill, power draft, fuel consumption, corn yield.

\section{INTRODUÇÃO}

Com o avanço da área implantada com o sistema de plantio direto (semeadura direta), muitos agricultores têm procurado alternativas para otimizar a capacidade operacional dos conjuntos trator/ semeadoras, bem como, procurar conviver com uma

IDepartamento de Solos, Faculdade de Agronomia, Universidade Federal do Rio Grande do Sul (UFRGS), Av. Bento Gonçalves, 7712, 91540-000, Porto Alegre, RS, Brasil. E-mail: renatole@ufrgs.br. Autor para correspondência.

IIDepartamento de Engenharia Rural, Faculdade de Ciências Agrárias e Veterinárias (FCAV), Universidade Estadual Paulista Júlio de Mesquita Filho (UNESP), Jaboticabal, SP, Brasil.

IIIDepartamento de Engenharia Rural, UNESP, Botucatu, SP, Brasil.

IV Programa de Pós-graduação em Ciência do Solo, UFRGS, Porto Alegre, RS, Brasil.

vPrograma de Pós-graduação em Ciência do Solo, UNESP, Jaboticabal, SP, Brasil. 
maior compactação do solo, notadamente da sua camada mais superficial, sem necessitar do uso de equipamentos mobilizadores do solo como escarificadores e/ou subsoladores (SECCO et al., 2004). Esses objetivos estão sendo atingidos, na prática, pelo uso de sulcadores de adubo com maior capacidade de aprofundamento e de mobilização do solo do que os discos duplos (BORDIGNON, 2005), bem como, realizando a semeadura no sentido do maior comprimento nas lavouras, que, muitas vezes, coincide com o sentido do declive. Em função da adoção dessas práticas, não se possui, até o momento, informações sobre o comportamento do conjunto trator/semeadora quando em operação nestas condições, especialmente quanto à capacidade operacional, patinagem dos rodados tratórios, consumo de combustível, força de tração, volume de solo mobilizado e, principalmente, sobre o comportamento e produtividade das culturas implantadas.

O tipo de sulcador de adubo utilizado nas semeadoras-adubadoras de precisão pode afetar o grau de mobilização do solo, a força de tração, a quantidade de plantas daninhas emergidas na linha de semeadura e a patinagem dos rodados do trator (SCHLOSSER et al.,1999; BEUTLER et al., 2003).

Segundo ASAE (1999), a força de tração necessária para operar semeadoras-adubadoras de precisão, em semeadura direta, sobre solo argiloso, varia entre 1,8 a $3,0 \mathrm{kN}$ por linha de semeadura, respectivamente, quando equipadas com sulcadores de adubo tipo discos duplos e haste. Em solos classificados como de textura média e arenosa, esses valores diminuem em torno de 15 e 25\%, respectivamente. Os valores citados podem variar em $\pm 25 \%$.

Em solos argilosos e em semeadura direta com emprego de sulcador de adubo tipo haste, CASÃO JÚNIOR et al. (2000) e DEBIASI (2008) obtiveram valores entre 2,0 e $3,8 \mathrm{kN}$ por linha de semeadura, dependendo da sua profundidade de trabalho, geometria e ângulo de ataque da haste e da ponteira com o solo, tipo de ponteira e teor de água do solo. CEPIK (2002) encontrou valores de esforço de tração medidos em haste sulcadora que variaram em torno de $1,1 \mathrm{kN}$ por linha da semeadora. A mesma autora obteve uma relação estreita entre o esforço de tração medido na haste com as variáveis profundidade de atuação e teor de água no solo, respondendo por $80 \%$ do resultado. A velocidade de deslocamento não teve influência significativa sobre a demanda de tração no solo testado, de textura média a argilosa.

JASA et al. (1992) citam como fatores influenciadores da demanda de potência na barra de tração do trator, em operação de semeadura, o tipo de solo, a velocidade de deslocamento, o número de linhas da semeadora-adubadora, o teor de água no solo, a configuração dos órgãos ativos em contato com o solo (tipo, formato e profundidade de atuação dos sulcadores) e seu peso total. Não menos importantes, os autores citam as condições de superfície e de subsuperfície do solo e, especificamente, do leito de semeadura, bem como a configuração do terreno em que o conjunto trator-semeadora está operando.

Dessa forma, espera-se que a semeadura, quando realizada em nível, ou então em aclive ou declive, proporcione diferenças em termos de desempenho tratóreo e da máquina de semeadura, interferindo na mobilização de solo em linha de semeadura e aspectos relacionados ao seu trabalho e consequentemente no desempenho da cultura, no caso o milho.

Para avaliar o efeito do sentido de operação, em nível e longitudinal ao declive do terreno, assim como do tipo de sulcador de adubo, haste sulcadora ou discos duplos e, em outras variáveis como demanda de esforço de tração, consumo de combustível e patinagem dos rodados tratórios na semeadura direta de milho sobre resteva de aveia preta, bem como verificar seu efeito sobre o solo e sobre a cultura do milho, foi realizado um ensaio a campo, com uma semeadora-adubadora de precisão de quatro linhas.

\section{MATERIAL E MÉTODOS}

O ensaio foi conduzido na Fazenda Experimental Lageado, FCA/UNESP, Botucatu, SP, tendo como localização geográfica $22^{\circ} 49^{\prime} \mathrm{S}$ e $48^{\circ} 25^{\prime} \mathrm{O}$, com altitude de 700, em solo Nitossolo Vermelho distroférrico latossólico (BRASIL, 1999), com declividade de $0,071 \mathrm{~m} \mathrm{~m}^{-1}$, o qual vinha sendo cultivado há dois anos em semeadura direta com a sucessão aveia preta-milho. A textura do solo é argilosa, com 500, 290 e $210 \mathrm{~g} \mathrm{~kg}^{-1}$ de argila, silte e areia, respectivamente. A semeadura da cultura da aveia preta (Avena strigosa Schreb) foi efetuada em contorno, ou seja, seguindo as curvas de nível do terreno, empregando-se uma semeadora-adubadora de fluxo contínuo, de arrasto, com 15 linhas espaçadas em 0,20m, sem preparo do solo (semeadura direta), na densidade de 100 sementes por metro, a velocidade de $5,5 \mathrm{~km} \mathrm{~h}^{-1}$. Na semeadura, não foi utilizada adubação de manutenção, porém, aplicou-se $45 \mathrm{~kg} \mathrm{ha}^{-1}$ de $\mathrm{N}$, na forma de uréia, a lanço, no estádio fenológico de perfilhamento da cultura.

A cultura da aveia preta foi dessecada no estádio denominado de “grão leitoso”, juntamente com 
as plantas daninhas, com herbicida de ação total $(1,5 \mathrm{~L}$ ha $^{-1}$ de glifosate), aplicado com pulverizador de barras tratorizado. Após a dessecação, foram coletadas amostras de resíduos culturais sobre o solo em áreas de $0,25 m^{2}$, para determinação da massa seca.

Na safra primavera-verão, foi implantada a cultura teste, nesse caso, o milho, em semeadura direta. Foram instalados dois experimentos, em que, no primeiro, a semeadura direta do milho foi realizada em nível, os tratamentos (sulcadores de adubo tipo haste e do tipo discos duplos) foram dispostos num delineamento inteiramente casualizado (DIC), com cinco repetições. No segundo, em que a semeadura direta do milho foi realizada no sentido do declive, os tratamentos (sulcadores de adubo tipo haste e discos duplos; semeadura em aclive ou declive) foram dispostos num delineamento de blocos casualizados, arranjo fatorial 2x2, com quatro repetições. As parcelas possuíam 35m de comprimento por $4 \mathrm{~m}$ de largura. Em cada experimento, foram demarcadas duas parcelas com as mesmas dimensões para obtenção de parâmetros relacionados à resistência ao rolamento da semeadoraadubadora em nível e em aclive.

Antecedendo a semeadura do milho, foram coletadas amostras de solo na camada de $0-20 \mathrm{~cm}$ de profundidade, as quais foram remetidas ao Laboratório de Análises de Solos da Faculdade de Agronomia da UNESP-Botucatu para obter uma caracterização química da área experimental e subsidiar a adubação para a cultura do milho.

No dia da semeadura, foram obtidos dados de resistência mecânica do solo à penetração na camada de até $0,30 \mathrm{~m}$ de profundidade em toda a área experimental (seis repetições por parcela), utilizando um penetrógrafo da marca Soiltest, cone com área basal de $0,005 \mathrm{~m}^{2}$ e com ângulo de $30^{\circ}$. Também foram coletadas amostras de solo para determinação do seu teor de água na profundidade de 0 a 0,30m, segundo metodologia EMBRAPA(1979).

A semeadura da cultura do milho foi realizada com uma semeadora-adubadora de precisão, de arrasto, com quatro linhas espaçadas de $0,90 \mathrm{~m}$. A semeadoraadubadora possuía discos de corte de resíduos, lisos, com 460mm (18”) de diâmetro a frente dos sulcadores, os quais foram: (i) tipo haste, com haste e ponteira com 0,03 m de espessura e com ângulo de inclinação da haste e de sucção da ponteira de $25^{\circ}$ e $34^{\circ}$, respectivamente; (ii) tipo discos duplos concêntricos com 410 mm (16”) de diâmetro, dotado de limpadores internos. Os sulcadores de sementes foram discos duplos concêntricos com 410mm (16”) de diâmetro, dotado de limpadores internos. O controle da profundidade de deposição das sementes foi exercido por duas rodas de borracha dispostas lateralmente aos sulcadores de sementes. A compactação controlada das sementes na linha de semeadura foi efetuada por rodas compactadoras de borracha em formato de "V" com 300mm (12”) de diâmetro.

A semeadora-adubadora trabalhou com $500 \mathrm{~kg}$ de adubo e $60 \mathrm{~kg}$ de sementes. Sua massa vazia é de $2.150 \mathrm{~kg}$. Foi tracionada por um trator tração 4x2 com TDA(Tração Dianteira Auxiliar), com 80kW de potência no motor. Durante a semeadura, a TDA não foi acionada. O trator estava dotado de pneus traseiros 18.4x30R1, inflados à $110 \mathrm{kPa}$ e foi operado na mesma marcha e rotação do motor em todos os tratamentos, para obterse uma velocidade média de $6,0 \mathrm{~km} \mathrm{~h}^{-1}$.

A dosagem de sementes (híbrido Cargil C435) e da adubação de base (fórmula 04-14-08) empregada foi de 6,3 sementes por metro e de $440 \mathrm{~kg}$ ha $^{-1}$, respectivamente. As sementes de milho possuíam $98 \%$ de pureza e poder germinativo de $85 \%$. Os discos de corte de resíduos, os sulcadores de adubo e os de sementes foram regulados para trabalhar a $0,04 \mathrm{~m}, 0,10 \mathrm{~m}$ e $0,05 \mathrm{~m}$ de profundidade, respectivamente.

Durante a operação de semeadura, foram avaliados a patinagem das rodas tratórias (traseiras) e o consumo de combustível do trator, bem como a força de tração na barra para tracionar a semeadoraadubadora (em operação de semeadura e em rolamento, ou seja, a máquina erguida e apoiada sobre seus rodados). Os materiais e a metodologia para obtenção desses dados foram descritos por SILVA \& BENEZ (1997) e GAMERO \& LANÇAS (1996), respectivamente. Imediatamente após a semeadura, foi medida a área de seção transversal de solo mobilizada pelos sulcadores, com auxílio de um perfilômetro, e a porcentagem de cobertura do solo por resíduos, segundo método descrito em SLONEKER \& MOLDENHAUER (1977). Aos 40 dias após a emergência do milho, quando se encontrava no estádio vegetativo entre 4 e 5 folhas verdadeiras, foi efetuada uma aplicação, a lanço e manualmente, de $90 \mathrm{~kg} \mathrm{ha}^{-1} \mathrm{de}$ $\mathrm{N}$, na forma de uréia (45-00-00).

Aos 30 e 60 dias após a semeadura e antes da colheita da cultura do milho foi efetuada a contagem do número de plantas, em locais pré-definidos nas parcelas (10m nas duas linhas centrais). Nesses mesmos locais, foram colhidas, manualmente, as espigas das plantas de milho. Depois de trilhados, os grãos foram pesados e sua umidade corrigida para 13\% para cálculo do rendimento de grãos.

Os dados obtidos foram submetidos à análise de variância e havendo significância $(\mathrm{P}<0,05)$ procedeu-se à comparação de médias pelo teste de Tukey a 5\% de probabilidade. Para a realização das análises, utilizou-se o software Estat, v.2.0. 


\section{RESULTADOS E DISCUSSÃO}

O solo das áreas experimentais apresentava, antes da semeadura do milho, níveis de $\mathrm{pH}\left(\mathrm{CaCl}_{2}\right) \mathrm{e}$ teores de nutrientes satisfatórios (médios a muito altos) na camada amostrada de 0 a $20 \mathrm{~cm}$ de profundidade $\left(\mathrm{pH}=5,1 ; \mathrm{P}=39 \mathrm{~g} \mathrm{dm}^{-3} ; \mathrm{K}=35 \mathrm{mmol}_{\mathrm{c}} \mathrm{dm}^{-3} ; \mathrm{Ca}\right.$ e $\mathrm{Mg}=19 \mathrm{e}$ $11 \mathrm{mmol}_{\mathrm{c}} \mathrm{dm}^{-3}$, respectivamente). $\mathrm{O}$ teor de matéria orgânica do solo nessa mesma camada era de $3 \%$. Porém, a saturação de bases do solo $(\mathrm{V} \%=45)$ estava ligeiramente abaixo do recomendado para a cultura do milho, segundo Boletim 100 (BOLETIM, 2006).

O estado físico do solo das áreas experimentais foi avaliado por meio da resistência mecânica do solo à penetração até a profundidade de $0,30 \mathrm{~m}$, no dia da semeadura do milho, sendo encontrados valores de Índice de Cone (IC) de 1.081 e $1.710 \mathrm{kPa}$ nas camadas de $0-15 \mathrm{~cm}$ e de $15-30 \mathrm{~cm}$, respectivamente. Como o teor médio de água na camada de solo avaliada era de $310 \mathrm{~g} \mathrm{~kg}^{-1}$, caracterizando estado de consistência friável a seco, pode-se inferir que o solo das áreas experimentais estava abaixo do limite de compactação genericamente aceito $(2.000 \mathrm{kPa})$, devido ao curto tempo de utilização com semeadura direta, subsequente a vários anos de uso com preparo convencional (REINERT et al., 2008).

Pelos dados da tabela 1 , verifica-se que a massa de resíduos de aveia sobre o solo, no dia da semeadura do milho, não diferiu entre os tratamentos, propiciando total e idêntica cobertura à superfície do solo. Durante o ciclo do milho, houve uma decomposição (perda de massa) média de $34 \%$ da palhada de aveia, quando a semeadura foi realizada em nível.

A utilização do sulcador tipo haste provocou uma mobilização $52 \%$ maior do solo na linha de semeadura, comparada à de discos duplos (Tabela 1). Essa variável é a provável explicação para que houvesse uma exigência maior de $32 \%$ na força média de tração, $60 \%$ nos picos de exigência de esforço na barra de tração e de $20 \%$ no consumo de combustível por área trabalhada, em relação ao uso do sulcador de discos na semeadura direta em nível (Tabela 1). GODWIN (2007) demonstra a influência dessas variáveis na demanda de tração, mobilização de solo e relações entre solo e ferramentas de preparo. No entanto, se a força de tração e o consumo de combustível forem relacionados à área e ao volume de solo mobilizado, o

Tabela 1 - Variáveis operacionais e da cultura, determinadas com a semeadora-adubadora em operação em nível, na semeadura do milho.

\begin{tabular}{|c|c|c|c|c|}
\hline \multirow{2}{*}{ Variáveis operacionais } & \multicolumn{4}{|c|}{ 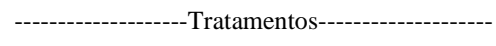 } \\
\hline & Hastes & Discos & Média & CV (\%) \\
\hline Massa de resíduos sobre o solo antes da semeadura do milho $\left(\mathrm{kg} \mathrm{ha}^{-1}\right)$ & $5.108 \mathrm{a}$ & $5.330 \mathrm{a}$ & 5.219 & 26,2 \\
\hline Capacidade de campo teórica (ha $\mathrm{h}^{-1}$ ) & $2.011 \mathrm{~b}$ & $2.089 \mathrm{a}$ & 2.050 & 0,9 \\
\hline Força de tração na BT $(\mathrm{kN})$ & 10,20 a & $7,72 \mathrm{~b}$ & 8,97 & 2,5 \\
\hline Força de tração por linha de semeadura $(\mathrm{N})$ & $2.550 \mathrm{a}$ & $1.930 \mathrm{~b}$ & 2.240 & 2,5 \\
\hline Potência média na BT (kW) & 15,83 a & $12,46 \mathrm{~b}$ & 14,14 & 2,7 \\
\hline Potência na BT, nos picos de exigência de força (kW) & 25,89 a & $16,08 \mathrm{~b}$ & 20,99 & 5,0 \\
\hline Potência operacional específica na barra $(\mathrm{kW} \mathrm{h} \mathrm{ha-1})$ & 7,88 a & $5,96 \mathrm{~b}$ & 6,92 & 2,5 \\
\hline Consumo horário de combustível $\left(\mathrm{L} \mathrm{h}^{-1}\right)$ & 11,34 a & $9,87 \mathrm{~b}$ & 10,61 & 4,5 \\
\hline Consumo operacional de combustível $\left(\mathrm{L} \mathrm{ha}^{-1}\right)$ & 5,64 a & $4,73 \mathrm{~b}$ & 5,18 & 4,2 \\
\hline Consumo de combustível em função da potência na barra ( $\left.\mathrm{L} \mathrm{h} \mathrm{kW}{ }^{-1}\right)$ & $0,72 \mathrm{~b}$ & 0,79 a & 0,75 & 5,2 \\
\hline Patinagem dos rodados do trator (\%) & 6,3 a & $4,0 \mathrm{~b}$ & 5,1 & 15,1 \\
\hline Cobertura do solo, após semeadura do milho (\%) & $82 \mathrm{a}$ & 83 a & 83 & 6,8 \\
\hline Profundidade de semeadura (cm) & $4,5 \mathrm{a}$ & $4,2 \mathrm{a}$ & 4,4 & 10,9 \\
\hline Volume de solo mobilizado pelo sulcador $\left(\mathrm{m}^{3} \mathrm{ha}^{-1}\right)$ & 95,2 a & $62,6 \mathrm{~b}$ & 78,9 & 21,0 \\
\hline Força de tração em função da área transversal de seção de solo mobilizada pelo sulcador $\left(\mathrm{N} \mathrm{cm}^{-2}\right)$ & $119,2 \mathrm{~b}$ & 137,2 a & 128,2 & 12,3 \\
\hline Consumo de combustível em função do solo mobilizado $\left(\mathrm{mL} \mathrm{m}^{-3}\right)$ & $59,2 \mathrm{~b}$ & 75,6 a & 67,4 & 11,2 \\
\hline População de plantas, por hectare, aos 30 DAS ${ }^{2}$ & $63.110 \mathrm{a}$ & $54.222 \mathrm{~b}$ & 58.667 & 8,3 \\
\hline População de plantas, por hectare, aos 50 DAS & 66.666 a & $59.444 \mathrm{~b}$ & 63.055 & 7,5 \\
\hline Plantas acamadas/quebradas, por ha, na época da colheita & $6.944 \mathrm{~b}$ & 10.278 a & 8.611 & 26,3 \\
\hline Massa de resíduos sobre solo na época da colheita do milho $\left(\mathrm{kg} \mathrm{ha}^{-1}\right)$ & $3.784 \mathrm{a}$ & $4.008 \mathrm{a}$ & 3.896 & 32,4 \\
\hline Rendimento de grãos da cultura do milho $\left(\mathrm{kg} \mathrm{ha}^{-1}\right)$ & 6.578 a & 6.346 a & 6.462 & 17,4 \\
\hline Rendimento do milho passível de colheita mecanizada $\left(\mathrm{kg} \mathrm{ha}^{-1}\right)$ & 5.898 a & $5.248 \mathrm{~b}$ & 5.573 & 11,6 \\
\hline
\end{tabular}

${ }^{1}$ Médias nas linhas seguidas de mesma letra não diferem entre si Tukey $(\mathrm{P}<0,05),{ }^{2}$ Dias após a semeadura 
sulcador de discos apresentou valores $15 \%$ e $27 \%$ superiores aos de hastes, respectivamente. Isso pode ter ocorrido devido à massa da semeadora, que exigiu, para resistência ao rolamento, $24 \%$ da força de tração verificada na semeadura, quando equipada com sulcador de hastes e 32\% quando com discos.

A patinagem do trator foi, também, maior com o uso de sulcador de hastes, o que implicou redução semelhante na capacidade operacional do conjunto trator-semeadora, embora o trator utilizado estivesse superdimensionado para trabalho com a semeadora. Esse fato resultou em baixos valores de patinagem, mesmo sem uso da TDA. O tipo de sulcadores de adubo da semeadora não afetou a porcentagem de cobertura, concordando com dados de CASÃO JÚNIOR et al. (2000), e nem a profundidade de semeadura do milho (Tabela 1). No entanto, a população de plantas foi $14 \%$ superior nos tratamentos com uso de hastes, na média das avaliações efetuadas aos 30 e 50 dias após a semeadura (Tabela 1). REIS et al. (2006), trabalhando em um Latossolo argiloso, concluíram que a densidade do solo na linha de semeadura foi menor para as hastes sulcadoras em comparação aos discos duplos, o que resultou em uma maior porcentagem de emergência de plantas de milho. A quantidade de plantas acamadas e quebradas foi $48 \%$ maior no tratamento com discos duplos, resultado, provavelmente, do menor grau de enraizamento em função do menor volume de solo mobilizado pelo sulcador de adubo. Essa quantidade de espigas teria grande chance de não poder ser colhida por colhedora autopropelida, munida de plataforma despigadora, resultando em elevadas perdas na colheita.

O consumo de combustível pelo trator em função da área trabalhada (Tabela 2) foi 17\% maior com uso do sulcador de haste em relação ao sulcador de discos duplos, o que também foi verificado quando a semeadura foi efetuada em nível (Tabela 1). $\mathrm{Na}$ semeadura em aclive, o consumo de combustível foi praticamente o dobro do consumido em declive, independentemente do tipo de sulcador utilizado. Esse fato é consequência da maior exigência de tração e da maior patinagem dos rodados, portanto, menor velocidade de deslocamento do conjunto tratorsemeadora. No entanto, não houve diferença de consumo de combustível entre semear um hectare em nível ou no sentido do aclive ou declive, fato este que, na prática, tem levado muitos agricultores a empregar esta última forma de semeadura, em virtude de ser operacionalmente mais rápida quando coincidir com o maior comprimento da lavoura, por necessitar menos manobras de cabeceira.

A patinagem dos rodados do trator (Tabela 2) foi $41 \%$ maior com uso do sulcador tipo haste, em relação ao de discos duplos, somente quando a semeadora foi operada em aclive. A patinagem dos rodados do trator foi 2,5 vezes maior quando a semeadora foi operada em aclive, em relação ao sentido em declive, independentemente do tipo de sulcador, o que pode ser explicado pela maior exigência de tração, para tracionar também a carga do conjunto tratorsemeadora (GABRIEL FILHO, et al., 2004). Esse fato também pode contribuir para a ocorrência do processo erosivo, pois a patinagem excessiva de rodados remove a cobertura do solo, cisalha a superfície e deixa um sulco orientado no sentido do declive, o que pode concentrar o escoamento em caso de chuvas de alta intensidade (LEVIEN et al., 1990).

A cobertura do solo por resíduos após a semeadura (Tabela 2) não foi influenciada pelos tratamentos, apresentando um valor médio de $88 \%$, semelhante ao verificado quando a semeadura foi efetuada em nível (Tabela 1). Embora com mesmo grau de cobertura sobre o solo, há diferenças quanto à facilitação do escoamento superficial e consequente probabilidade de ocorrência de erosão em sulcos quando estes são orientados no sentido do declive/ aclive, no momento em que a taxa de precipitação excede a taxa de infiltração de água do solo. A profundidade de semeadura do milho (Tabela 2) não foi afetada pelo sentido da semeadura e atingiu o valor desejado $(5 \mathrm{~cm})$ apenas quando se empregou o sulcador tipo haste. Com essa ferramenta, a deposição da semente no sulco de semeadura foi em torno de $1 \mathrm{~cm}$ mais profundo do que com discos duplos, o que pode ter influenciado na resistência das plantas de milho ao tombamento, em especial, por ventos. Não houve influência dos tratamentos sobre a decomposição dos resíduos de aveia preta durante o ciclo de desenvolvimento da cultura do milho. À época da colheita do milho, a quantidade média de resíduos (3.449 $\mathrm{kg} \mathrm{ha}^{-1}$ ) foi muito semelhante à obtida no experimento em que a semeadura foi efetuada em nível (Tabela 1), ocorrendo idêntica redução (33\%) em relação à massa inicial avaliada antes da semeadura.

A produtividade de grãos da cultura de milho semeada em nível não apresentou diferença significativa entre os tipos de sulcadores testados (Tabela 2), discordando de MELLO et al. (2003), que obtiveram $11 \%$ a mais de grãos nos tratamentos em que empregaram com sulcador de adubo do tipo haste. Porém, se considerarmos que a produtividade de grãos das plantas acamadas e quebradas não seria passível de colheita mecanizada por meio de colhedora munida de plataforma despigadora, o tratamento com sulcador de haste apresentou uma diferença significativa de $650 \mathrm{~kg} \mathrm{ha}^{-1}$, em relação à da obtida com sulcador de adubo do tipo discos duplos. 
Tabela 2 - Variáveis determinadas com semeadora-adubadora de milho equipada com dois tipos de sulcadores e operando em aclive e em declive.

\begin{tabular}{|c|c|c|c|}
\hline \multirow{2}{*}{ Sentido de deslocamento } & \multicolumn{2}{|c|}{ 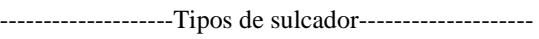 } & \multirow{2}{*}{ Médias } \\
\hline & Hactes & Dicco dulul & \\
\hline & \multicolumn{3}{|c|}{ 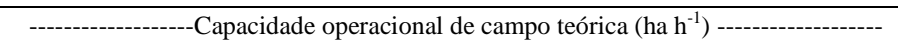 } \\
\hline Em declive & 2,064 & 2,132 & $2,099 \mathrm{a}$ \\
\hline Em aclive & 1,876 & 1,964 & $1,920 \mathrm{~b}$ \\
\hline \multirow[t]{2}{*}{ Médias } & $1,970 \mathrm{~B}$ & $2,049 \mathrm{~A}$ & 2,009 \\
\hline & \multicolumn{3}{|c|}{-------------------------Volume de solo mobilizado $\left(\mathrm{m}^{3} \mathrm{ha}^{-1}\right)$----------------------- } \\
\hline Em declive & 100,6 & 55,0 & 77,8 a \\
\hline Em aclive & 107,7 & 60,2 & 83,9 a \\
\hline \multirow[t]{2}{*}{ Médias } & $104,1 \mathrm{~A}$ & $57,6 \mathrm{~B}$ & 80,9 \\
\hline & \multicolumn{3}{|c|}{ 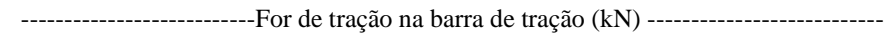 } \\
\hline Em declive & 9,60 & 7,23 & $8,42 \mathrm{~b}$ \\
\hline Em aclive & 12,48 & 9,66 & 11,07 a \\
\hline \multirow[t]{2}{*}{ Médias } & $11,04 \mathrm{~A}$ & $8,45 \mathrm{~B}$ & 9,74 \\
\hline & \multicolumn{3}{|c|}{-----Força de tração na barra, em função da seção de solo mobilizada $\left(\mathrm{N} \mathrm{cm}^{-2}\right)$----- } \\
\hline Em declive & 106,0 & 146,1 & $126,1 \mathrm{~b}$ \\
\hline Em aclive & 128,8 & 178,3 & $153,6 \mathrm{a}$ \\
\hline \multirow[t]{2}{*}{ Médias } & $117,4 \mathrm{~B}$ & $162,2 \mathrm{~A}$ & 140,0 \\
\hline & \multicolumn{3}{|c|}{ 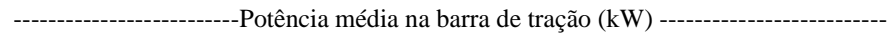 } \\
\hline Em declive & 15,30 & 11,89 & $13,59 \mathrm{~b}$ \\
\hline Em aclive & 18,06 & 14,65 & $16,35 \mathrm{a}$ \\
\hline \multirow[t]{2}{*}{ Médias } & $16,68 \mathrm{~A}$ & $13,27 \mathrm{~B}$ & 14,97 \\
\hline & \multicolumn{3}{|c|}{ 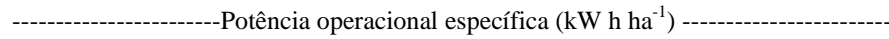 } \\
\hline Em declive & 7,41 & 5,58 & $6,50 \mathrm{~b}$ \\
\hline Em aclive & 9,63 & 7,46 & 8,55 a \\
\hline \multirow[t]{2}{*}{ Médias } & $8,52 \mathrm{~A}$ & $6,52 \mathrm{~B}$ & 7,52 \\
\hline & \multicolumn{3}{|c|}{ 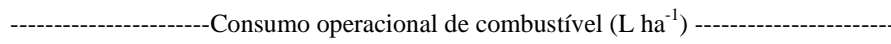 } \\
\hline Em declive & 3,86 & 3,37 & $3,62 \mathrm{~b}$ \\
\hline Em aclive & 7,71 & 6,51 & $7,11 \mathrm{a}$ \\
\hline \multirow[t]{2}{*}{ Médias } & $5,78 \mathrm{~A}$ & $4,94 \mathrm{~B}$ & 5,36 \\
\hline & \multicolumn{3}{|c|}{-Consumo de combustível por volume de solo mobilizado pelo sulcador $\left(\mathrm{mL} \mathrm{m} \mathrm{m}^{-3}\right.$ ) - } \\
\hline Em declive & 38,6 & 61,3 & $50,0 \mathrm{~b}$ \\
\hline Em aclive & 71,6 & 108,1 & 89,9 a \\
\hline \multirow[t]{2}{*}{ Médias } & $55,1 \mathrm{~B}$ & $84,7 \mathrm{~A}$ & 70,0 \\
\hline & \multicolumn{3}{|c|}{---Consumo de combustível em função da potência exigida na barra $(\mathrm{L} \mathrm{h} \mathrm{kW-1})$--- } \\
\hline Em declive & 0,52 & 0,61 & $0,56 \mathrm{~b}$ \\
\hline Em aclive & 0,80 & 0,87 & 0,84 a \\
\hline Médias & $0,66 \mathrm{~B}$ & $0,74 \mathrm{~A}$ & 0,70 \\
\hline & ------- & rodas traseira & --------- \\
\hline Em declive & 3,4 bA & $2,7 \mathrm{bA}$ & 3,1 \\
\hline Em aclive & $12,7 \mathrm{aA}$ & 9,0 aB & 10,9 \\
\hline Médias & 8,1 & 5,9 & 7,0 \\
\hline & --------- & de semeadura & ---------- \\
\hline Em declive & 4,6 & 3,6 & 4,1 a \\
\hline Em aclive & 4,5 & 3,8 & $4,1 \mathrm{a}$ \\
\hline Médias & $4,6 \mathrm{~A}$ & $3,7 \mathrm{~B}$ & 4,1 \\
\hline & ------- & rãos da cultura & -------- \\
\hline Em declive & 7.063 & 6.406 & 6.735 a \\
\hline Em aclive & 6.444 & 6.484 & $6.464 \mathrm{a}$ \\
\hline Médias & $6.754 \mathrm{~A}$ & $6.445 \mathrm{~A}$ & 6.600 \\
\hline & ---------1 & ssível de colhe & )--------- \\
\hline Em declive & 6.061 & 4.779 & $5.420 \mathrm{a}$ \\
\hline Em aclive & 5.630 & 4.978 & $5.304 \mathrm{a}$ \\
\hline Médias & $5.846 \mathrm{~A}$ & $4.878 \mathrm{~B}$ & 5.362 \\
\hline
\end{tabular}

Em cada variável, médias seguidas de mesma letra minúscula na coluna e maiúscula na linha não diferem significativamente Tukey (P<0,05)

Ciência Rural, v.41, n.6, jun, 2011. 
Analisando os dados da tabela 2, verificase que a exigência de tração da semeadora foi $18 \%$ maior com uso de sulcador de adubo tipo haste e 31\% maior quando a semeadora foi operada em aclive, em relação ao sulcador de discos duplos e operação em declive, respectivamente. A resistência ao rolamento da semeadora-adubadora em declive foi de $4,47 \mathrm{kN}$, ou seja, $40 \%$ da força de tração média quando em operação de semeadura, na média dos sulcadores de discos duplos e haste. Na média dos sentidos aclive/declive $(9,74 \mathrm{kN})$, a exigência de tração foi semelhante à operação executada em nível $(8,97 \mathrm{kN})$, já que o teor de água e os demais atributos físicos do solo nas duas condições foram idênticos. Dados que corroboram esses apresentados acima foram obtidos por LEVIEN (1999).

O volume de solo mobilizado na operação de semeadura do milho (Tabela 2) não foi influenciado pelo sentido da operação (aclive/declive), mas, à semelhança do verificado na semeadura em nível (Tabela 1), foi 80\% maior com uso do sulcador de adubo tipo haste do que com o de discos duplos, explicando, em parte, a maior exigência de tração deste órgão. Os valores foram semelhantes aos obtidos no experimento em nível (Tabela 1). A população de plantas de milho e a quantidade de plantas acamadas ou quebradas na época da colheita não diferiram entre os sentidos de deslocamento, obtendo-se valores médios de 51.250 e 16.150 plantas por hectare, respectivamente. O rendimento de grãos de milho também não diferiu entre os tratamentos, tipo de sulcador e sentido de deslocamento, apresentando média de $6.600 \mathrm{~kg} \mathrm{ha}^{-1}$, ou seja, 110 sacas por hectare. No entanto, quando se descontou a produção de grãos devida às plantas acamadas ou quebradas, sendo assim, não passíveis de colheita por colhedora autopropelida munida de plataforma despigadora, obteve-se uma redução na produtividade média de grãos de $13 \%$ e $25 \%$, quando a semeadora estava equipada com sulcadores do tipo facão e de discos duplos, respectivamente (Tabela 2). Esta quantidade de grãos se constituiria em perda de colheita, caso não houvesse um posterior recolhimento manual de espigas caídas sobre o solo. Desse modo, o uso do sulcador de adubo do tipo haste teve um efeito positivo sobre a produtividade da cultura do milho, em relação ao uso de discos duplos, por mobilizar maior volume de solo na linha de semeadura e, possivelmente, promovendo maior enraizamento das plantas e tornando-as mais resistentes ao tombamento.

\section{CONCLUSÃO}

A semeadura contra o declive e o uso de sulcador tipo haste implicaram maior demanda de esforço de tração, patinagem do trator e consumo de combustível por área trabalhada e não influenciaram o volume de solo mobilizado, a população de plantas e a produtividade de grãos do milho, em relação à operação realizada em declive e uso de sulcador de adubo de discos duplos, respectivamente.

A utilização de sulcador do tipo facão resultou em menor número de plantas acamadas e quebradas, em relação ao uso de discos duplos, independentemente do sentido da operação de semeadura.

A principal diferença entre semear em nível ou em aclive/declive é a formação de sulcos orientados a favor do declive, especialmente pela ação de sulcadores do tipo haste e elevada patinagem dos rodados do trator, já que o consumo de combustível por área trabalhada e capacidade operacional não foram influenciados por esses tratamentos.

\section{REFERÊNCIAS}

AMERICAN SOCIETY OF AGRICULTURAL ENGINEERS. Agricultural machinery management data. In: ASAE standards 1999: standards engineering practices data. San Joseph, 1999. p.359-366. (ASAE D497.4 JAN98).

BRASIL. Ministério da Agricultura e do Abastecimento. Empresa Nacional de Pesquisa Agropecuária. Centro Nacional de Pesquisa de Solos. Sistema brasileiro de classificação de solos. Brasília: EMBRAPA, 1999. 412p.

BEUTLER, J.F. et al. Patinagem do trator em sistemas de preparo do solo e semeadura. In. CONGRESO ARGENTINO DE INGENIARÍA AGRÍCOLA, 2003, Balcarce. Resumenes... Balcarce, Argentina: INTA, 2003. CD- Rom.

BOLETIM TÉCNICO DO INSTITUTO AGRONÔMICO. Campinas: Instituto Agronômico, 2006. 285p. (Boletim n.100).

BORDIGNON, J. Projeto, construção e desenvolvimento de transdutores para medição de esforços em semeadoras-adubadoras. 2005. 122f. Dissertação (Mestrado em Engenharia Mecânica) - Escola de Engenharia, Universidade Federal do Rio Grande do Sul, Porto Alegre, RS.

CEPIK, C.T.C. Análise do desempenho de uma haste sulcadora de semeadora adubadora, em diferentes teores de água no solo, velocidades e profundidades de trabalho. 2002. 60f. Dissertação (Mestrado em Ciência do Solo) Faculdade de Agronomia, Universidade Federal do Rio Grande do Sul, Porto Alegre, RS.

CASÃO JÚNIOR, R. et al. Desempenho da semeadoraadubadora Magnum 2850 em plantio direto no basalto paranaense. Pesquisa Agropecuária Brasileira, Brasília, v.35, n.3, p.523-532, 2000. Disponível em: <http:// www.scielo.br/scielo.php?script=sci_arttext\&pid=S0100204X2000000300007\&lang=pt>. Acesso em: 18 abr. 2011. doi: 10.1590/S0100-204X2000000300007.

DEBIASI, H. Recuperação física de um Argissolo compactado e suas implicações sobre o sistema solo- 
máquina-planta. 2008. 263f. Tese (Doutorado em Ciência do Solo) - Faculdade de Agronomia, Universidade Federal do Rio Grande do Sul, Porto Alegre, RS.

EMBRAPA. Serviço Nacional de Levantamento e Conservação de Solos. Manual de métodos de análise de solo. Rio de Janeiro:SNLCS, 1979. 225p.

GABRIEL FILHO, A. et al. Desempenho de um trator operando em solo com diferentes tipos de cobertura vegetal. Engenharia Agrícola, Jaboticabal, v.24, n.3, p.781-789, 2004. Disponível em: $<$ http://www.scielo.br/scielo.php?script=sci_arttext\&pid=S010069162004000300032\&lang=pt $>$. Acesso em: out. 2010. doi: 10.1590/S0100-69162004000300032.

GAMERO, C.A., LANÇAS, K.P. Ensaio e certificação das máquinas de mobilização periódica do solo. In: MIALHE, L.G. Máquinas agrícolas: ensaios e certificação. Piracicaba: Fundação Estudos Agrários Luiz Queiroz, 1996. p.463-514.

GODWIN, R.J. A review of the effect of implement geometry on soil failure and implement forces. Soil Tillage Research, Amsterdam v.97, p.331-340, 2007. Disponível em: <http:// w w w. s c i e n c e d i r e c t. c o m / science?_ob=ArticleURL\&_udi=B6TC6-4KPFKCD18 _user=687304\&_coverDate $=12 \% 2 F 31 \% 2 F 2007 \&$ alid $=1722263$ $971 \& \_r d o c=3 \&$ fmt $=$ high \&_orig $=$ search \&_origin=search \&_zo ne $=$ rslt_list_item \&_cdi $=5162 \&$ \&sort $=r \&$ \&t $=13 \&$ \& docanchor $=\&$ view $=$ c\&_ct=3\&_acct $=C 000037798 \&$ _version $=1$ \&_urlVersion $=0$ \&_userid $=$ 687304\&md5=570aa8c77119b43da89fb67b232298c8\&searchtype=a>. Acesso em: fev. 2010. doi:10.1016/j.still.2006.06.010.

JASA, P.J. et al. No-till drills. In: CONSERVATION tillage systems and management: crop residue management with no-till, ridge-till, mulch-till. Ames: Midwest Plan Service, 1992. p. 98-101.

LEVIEN, R. Condições de cobertura e métodos de preparo do solo para a implantação da cultura do milho (Zea mays L.). 1999. 305f. Tese (Doutorado em Agronomia, área de concentração Energia na Agricultura) - Faculdade de Ciências Agronômicas, Universidade Estadual Paulista, Botucatu, SP.
LEVIEN, R. et al. Erosão na cultura do milho em diferentes sistemas de cultivo anterior e métodos de preparo do solo. Revista Brasileira de Ciência do Solo, Campinas, v.14, n.1, p.73-80, 1990.

MELLO, L.M.M et al. Distribuição de sementes e produtividade de grãos da cultura do milho em função da velocidade de semeadura e tipos de dosadores. Engenharia Agrícola, Jaboticabal, v.23, p.563-567, 2003.

REINERT, D.J. et al. Limites críticos de densidade do solo para o crescimento de raízes de plantas de cobertura em argissolo vermelho. Revista Brasileira de Ciência do Solo, Viçosa, v.32, p.1805-1816, 2008. Disponível em: <http://w3.ufsm.br/ fisicadosolo/downloads/Producao_Artigos/41.pdf $>$. Acesso em: fev. 2010.

REIS, E.F. al. Densidade do solo no ambiente solo-semente e velocidade de emergência em sistema de semeadura de milho. Revista Brasileira de Ciência do Solo, Viçosa, v.30, n.5, p.777-785, 2006.

SECCO, D. et al. Produtividade da soja e propriedades físicas de um Latossolo submetido a sistemas de manejo e compactação. Revista Brasileira de Ciência do Solo, Viçosa, v.28, n.5, p.797-804, 2004. Disponível em: <http://www.scielo.br/ s cielo.ph p ? s c ri p t = s ci_art tex t \& pid = S 0100 06832004000500001\&lang=pt>. Acesso em: dez. 2009. doi: 10.1590/S0100-06832004000500001.

SCHLOSSER, J.F. et al. Desempenho de três mecanismos sulcadores de semeadura na presença de diferentes culturas destinadas a cobertura de inverno. Engenharia Agrícola, Jaboticabal, v.19, n.1, p.64-70, 1999.

SILVA, S.L.; BENEZ, S.H. Construção de sistema de aquisição de dados para avaliação do desempenho energético de máquinas e implementos agrícolas em ensaios de campo. Energia na Agricultura, Botucatu, v.12, p.10-15, 1997.

SLONEKER, L.L.; MOLDENHAUER, W.C. Measuring the amounts of crop residue after tillage. Journal Soil Water Conservation, Ankeny v.32, p.231-236, 1977. 